\title{
Design editorial e imprensa comunitária: redesign de um jornal de bairro de Curitiba
}

\author{
Editorial design and community press: redesign of a local newspaper \\ in Curitiba
}

\author{
LIU, Eunice \\ Universidade Tecnológica Federal do Paraná - UTFPR I euniceliu@utfpr.edu.br \\ HAMMERSCHMIDT, Christopher \\ Universidade Tecnológica Federal do Paraná - UTFPR I chdeutschbr@yahoo.com.br \\ OYAFUSO, Ângela Mayume \\ Universidade Tecnológica Federal do Paraná - UTFPR \\ I angelaoyafuso@alunos.utfpr.edu.br \\ SCHELBAUER, Renata \\ Universidade Tecnológica Federal do Paraná - UTFPR I renata.schelbauer@gmail.com
}

\begin{abstract}
Resumo
Este artigo relata o projeto de redesign do jornal de bairro Cidade Notícias, que circula em Curitiba. Primeiramente, apresentam-se dados de contextualização sobre o teor do jornal e aspectos gerais de sua apresentação visual. Em seguida, descrevem-se as etapas metodológicas, adaptadas da sequência relatada por Sless (2003): (1) delimitação do escopo; (2) análise de similares; (3) projeto e prototipagem; (4) conversação e refinamento; (5) especificação e produção; (6) monitoramento. A partir de tais definições, expõem-se detalhes acerca do trabalho de redesign, incluindo tópicos relacionados a formato, grid e layout, tipografia e redesign da marca. Como resultado, tem-se o novo padrão de diagramação e identidade visual de Cidade Notícias, aplicado à capa do jornal e a uma dupla de páginas internas, como modelo para edições futuras. Por fim, tecem-se algumas reflexões sobre o trabalho

\section{Abstract}

This paper reports on the redesign of Cidade Notícias, a community newspaper published in Curitiba. First, it presents background data about content and general features regarding the visual layout of the newspaper. Then, it describes the methodological steps, based on the sequence suggested by Sless (2003): (1) scoping; (2) benchmarking; (3) prototype development; (4) conversation and refinement; (5) specification and production; and (6) monitoring. From these definitions, the paper details the redesign project, including topics such as format, grid and layout, typography, and brand redesign. The result is a new composition pattern and visual identity for Cidade Notícias, applied to the newspaper cover page and an inner spread as a template for future editions. Finally, this paper brings reflections on the work developed as well as notes for the project continuity.
\end{abstract} desenvolvido, bem como apontamentos para a continuidade do projeto.

Palavras Chave: Design editorial. Tipografia. Jornal.

Keywords: Editorial design. Typography. Newspaper. 


\section{INTRODUC̣ÃO}

Ainda é possível encontrar alguns "nonni", como são chamados os avós italianos, das gerações imigrantes e precursoras do Bairro de Santa Felicidade, na região noroeste da cidade de Curitiba, no Paraná. Eles carregam a história da formação da maior cidade do sul do Brasil, originalmente referida pelos nativos tupi-guaranis como Curii Tiba, que significa pinheiral, nome atribuído pela exuberante terra povoada por araucárias. No século XVIII, a cidade se tornou lar para imigrantes de diversas origens, dentre os quais se encontravam os italianos. Estes se estabeleceram na região, carregando para ali suas tradições e culturas, que se mesclaram ao regionalismo local.

Gerações de pais, filhos e netos, descendentes dessas famílias, marcaram a cultura da região e desejaram registrar suas histórias, bem como trazer voz à comunidade local. Dessa maneira, teve origem no ano 2.000, de modo amador, o Jornal de Bairro Cidade Notícias (Figura 1), uma publicação filiada à Associação dos Jornais de Bairros de Curitiba (AJBC). O jornal teve por intuito, desde sua origem, apresentar notícias de interesse local, com linguagem e temas próximos ao dia a dia das pessoas que viviam na região, atingindo os moradores de maneira diferenciada à dos grandes veículos de comunicação. Em formato tabloide, caracterizado por notícias curtas e forte presença de imagens, Cidade Notícias possui distribuição gratuita, periodicidade mensal - embora já tenha circulado quinzenalmente - com tiragem de 10.000 exemplares, difundidos no bairro de Santa Felicidade e regiões circunvizinhas há dezoito anos, estando em sua 310a edição. Os produtores de conteúdo da publicação - editores, jornalistas, fotógrafos, diagramadores etc. - são pessoas da própria comunidade. O projeto gráfico do jornal impresso também nasceu assim, sendo lido hoje por um público estimado de 40.000 pessoas, com uma reconhecível relação de proximidade e integração estabelecida com o público leitor local.

Figura 1 - Jornal de bairro Cidade Notícias, distribuído na região de Santa Felicidade, Curitiba
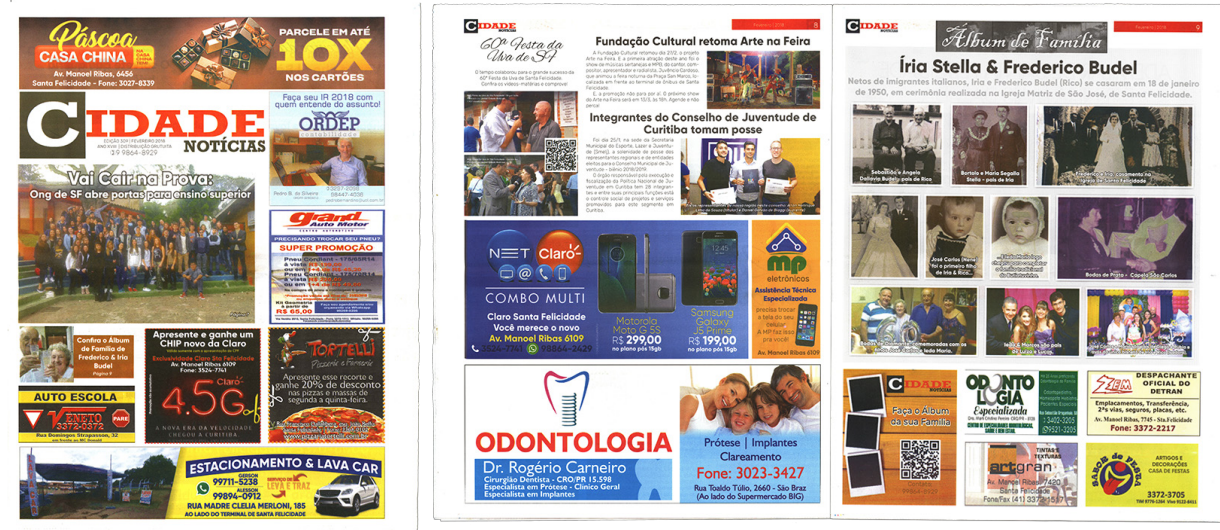

Fonte: Acervo Cidade Notícias (ed. 309, 2017). 
O Jornal Cidade Notícias foi o objeto de nosso estudo e pesquisa, o qual permitiu uma aproximação entre a Universidade Tecnológica Federal do Paraná (UTFPR) e a comunidade local de Curitiba. Isso se deu pela realização do projeto de iniciação científica intitulado Redesign de Jornal de Bairro de Curitiba, com o propósito de realizar pesquisa, envolvendo os quatro autores, de soluções editoriais por meio do exercício em um projeto real de redesenho do jornal.

\section{ASPECTOS GERAIS DA APRESENTAC̣ÃO VISUAL DE CIDADE NOTÍCIAS}

Em um primeiro momento da pesquisa, notou-se a ausência de identidade visual nas edições passadas de Cidade Notícias, sendo difícil diferenciar o jornal de um tabloide publicitário. A primeira página (capa) frequentemente apresentava um visual poluído e pouco atrativo, com forte presença de anúncios e imagens, que em geral se encontravam em baixa qualidade. As edições, variando entre 16 a 32 páginas, possuíam pouca padronização de diagramação, misturando texto, imagens e anúncios de modo desordenado, com espaçamentos irregulares, o que, somado às deficiências apontadas anteriormente, dificulta o estabelecimento de unidade editorial, além de comprometer a legibilidade do tabloide. A soma de tais fatores desfavorece também a construção de identidade, atenuando o valor e a credibilidade do tabloide, apesar de sua importância local.

Uma aprofundada análise da visualidade do tabloide evidenciou deficiências no design editorial, como o uso irregular e variações de versões da marca Cidade Notícias, ausência de uma paleta de cores definida na identidade do jornal, variações despadronizadas de estrutura gráfica, colunas e grid, erros de alinhamento, extravasamentos de margens, ausência de linguagem visual e qualidade fotográfica, falta de hierarquia entre elementos de página, descuidada escolha tipográfica etc., dentre algumas deficiências apontadas na Figura 2.

Figura 2 - Poluição visual nas páginas do jornal Cidade Notícias.
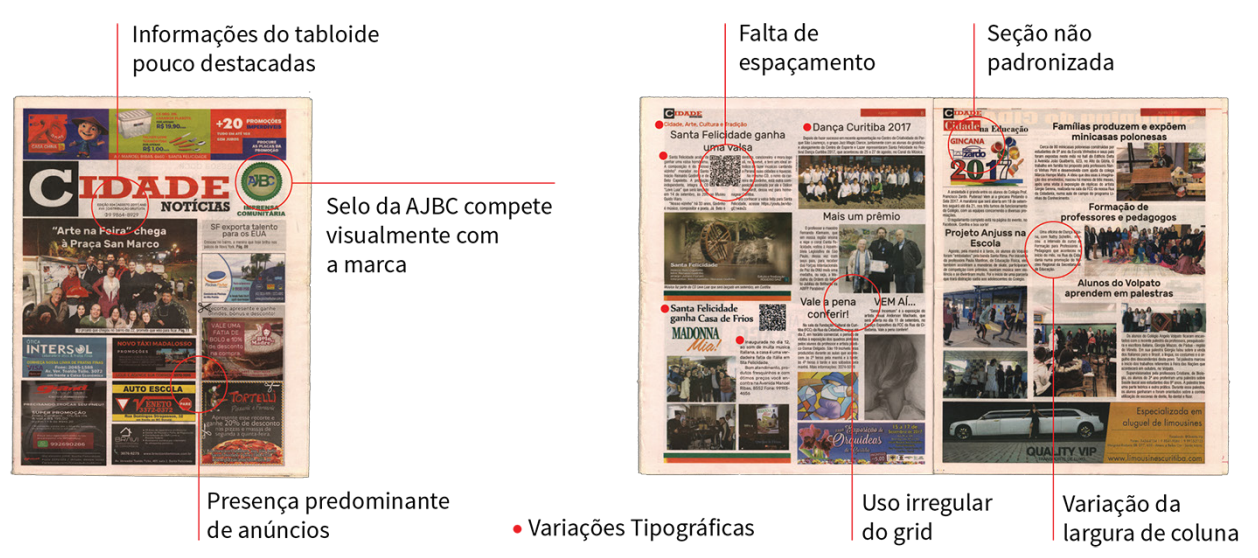

Fonte: Acervo Cidade Notícias (ed. 304, 2017).

Projética, Londrina, v.9, n.2 supl. p. 333-348, nov. 2018 
Sobre os elementos de composição editorial, Munari (2002, p. 25) relaciona: "a escolha dos caracteres tipográficos de acordo com o assunto, a definição da mancha do texto em relação à página, o local da numeração das páginas, as páginas de rosto, o caráter visual das ilustrações ou fotografias que acompanham o texto, e assim por diante". O autor evidencia a importância de cada parte do projeto e a relação entre elas, de modo a realizar um bom design editorial, onde a harmonia visual favorece a legibilidade da mídia, seguindo "leis do design harmonioso" (TSCHICHOLD, 1949, p. 25), apontadas pelo tipógrafo Jan Tschichold.

Este panorama foi oportuno para a realização do novo projeto do Cidade Notícias, que, partindo do conteúdo existente em edições passadas, intencionou alcançar a harmonia citada, por meio de uma melhor qualidade gráfica e articulação entre os elementos visuais envolvidos no projeto editorial do tabloide.

\section{METODOLOGIA}

Os procedimentos metodológicos adotados para a execução da pesquisa e o redesign do jornal Cidade Notícias seguiram cinco etapas, conforme listadas a seguir:

1. Briefing e delimitação do escopo: esta fase consistiu em reuniões com o diretor do jornal, Bryan Schellin, visando a conhecer a história do veículo, entender aspectos práticos - como produção de conteúdo, organização da informação, produção e distribuição -, analisar o público-alvo e determinar as necessidades a serem supridas pelo projeto de redesign, conforme apresentado anteriormente;

2. Fundamentação teórica: uma vez demarcado o contexto do trabalho, buscou-se o embasamento teórico pertinente à realização do projeto, o que se deu sobretudo por meio de leitura e fichamento de livros da área editorial, conforme citado neste artigo;

3. Análise gráfica de jornais: paralelamente à fundamentação, realizouse a análise de uma amostra de projetos de jornais nacionais e internacionais, considerados exemplos de boas práticas no design editorial, apresentada sucintamente no item Grid e Layout;

4. Estudos de tipografia e diagramação: esta etapa marcou o início das atividades práticas, com o desenvolvimento de propostas de grid, análise de famílias tipográficas, legibilidade, rendimento, adequação à proposta do jornal e determinação da mancha gráfica, macro e microtipografia, que resultaram na proposta de redesign;

5. Estudos de marca: juntamente com o projeto de diagramação do jornal, detectou-se a necessidade de adequar a marca ao novo projeto. Isso se fez por meio de estudos de tipografia e composição para o nome Cidade Notícias, 
buscando-se um equilíbrio entre a marca já existente e a reestruturação gráfica proposta para o jornal.

As ações realizadas, apresentadas neste artigo, se estenderam até o limite das etapas projetuais de desenvolvimento do trabalho, com algumas iterações de conversação e refinamento. Posteriormente, serão especificados aspectos de produção e seguinte monitoramento, conforme o modelo cíclico de processo de design proposto por Sless (2003), sintetizado na Figura 3.

Figura 3 - Modelo cíclico de processo de design.

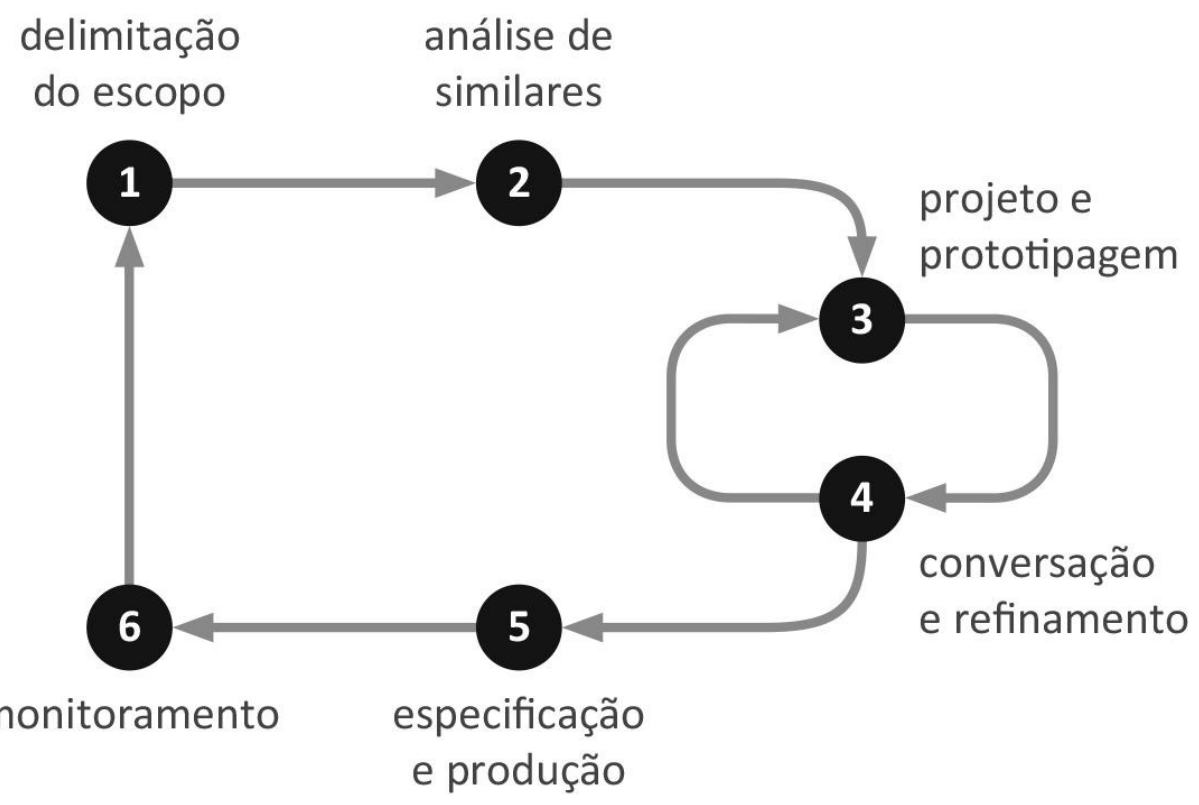

Fonte: Adaptado de Sless (2003).

\section{REDESIGN DO JORNAL}

\subsection{Formato}

Pesquisa histórica de edições passadas do Cidade Notícias, assim como de projetos gráficos de tabloides similares circulantes na cidade de Curitiba - especialmente aqueles filiados à AJBC, apresentados no Quadro 1 - deram início à pesquisa, seguidos de uma breve comparação com outros jornais nacionais e internacionais. Os diversos exemplares das publicações disponibilizadas pela associação formaram um rico material de base para levantamento de dados, como formato e soluções gráficas (Figura 4). Tais análises se mostraram fundamentais para o estudo da materialidade do jornal físico enquanto meio de comunicação e na definição do formato para o jornal, além das dimensões internas de margens, localização dos elementos de página etc., avaliando do formato para o conteúdo de página, do conteúdo de página para o formato. 
Tendo a sua origem em meados do século $X X$, o formato tabloide surgiu caracterizado por ser mais compacto em tamanho e conteúdo jornalístico e foi adotado pela maior parte dos associados à $A J B C$, possuindo alguma variação dos tamanhos tabloides padrões (Quadro 1). A comparação dos formatos foi conclusiva quanto ao fato de que a maior parte se utiliza da medida $28 \times 38 \mathrm{~cm}$, a qual, em sua origem, foi também definida pelo ótimo aproveitamento de papel de gráfica. Decidiu-se então manter o formato original do Cidade Notícias.

Figura 4 - Análise de jornais e tablóides.

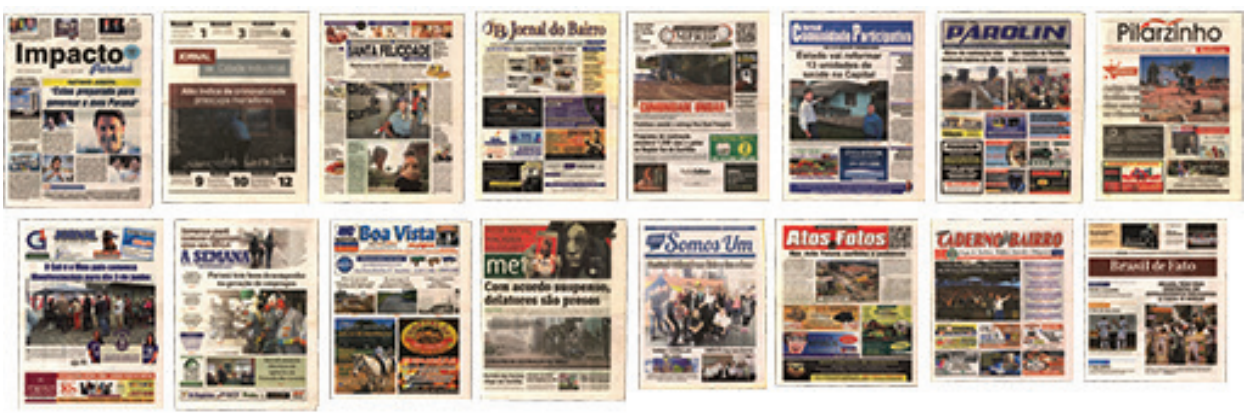

Fonte: Acervo AJBC (2017).

Quadro 1 - Medidas de tabloides curitibanos.

\begin{tabular}{ll}
\hline Dimensões $(\mathbf{c m})$ & Jornais da amostra analisada \\
\hline $25,5 \times 35,0$ & Somos Um \\
$27,0 \times 35,0$ & Atos e Fotos \\
$28,0 \times 38,0$ & A Semana \\
$28,5 \times 31,5$ & Caderno do Bairro; Brasil de Fato \\
$29,0 \times 37,0$ & Jornal Boa Vista em Páginas \\
$29,0 \times 35,0$ & Metro Curitiba \\
$29,0 \times 38,0$ & Folha Santa Felicidade; Jornal do Bairro; Gazeta Campo Comprido; \\
& Jornal Comunidade Participativa; Jornal Amigos do Bairro; Jornal do \\
$29,5 \times 38,0$ & Parolin; Jornal da Cidade Industrial \\
$29,0 \times 39,0$ & Pilarzinho \\
\hline
\end{tabular}

Fonte: Acervo AJBC (2017).

\subsection{Grid e Layout}

Além das publicações citadas anteriormente, analisaram-se os exemplos internacionais The New York Times, NYT Book Review, Nara Nara e Quimera, bem como os nacionais Quatro cinco um e Folha de São Paulo, com foco na estrutura gráfica, composição de grid e layout. Nessas análises, verificouse detalhes acerca de formato, estrutura de grid, composição, elementos de página, hierarquia de informação e outros pormenores relevantes para o projeto. Conforme salientam Ambrose e Harris (2009), os layouts gráficos apresentam áreas mais ativas ou centrais, enquanto outras possuem caráter 
periférico. Isso influencia a forma como o olho humano examina os elementos visuais e conhecer essa dinâmica proporciona aos designers a possibilidade de direcionar a localização dos componentes de página, tornando-os mais ou menos perceptíveis aos leitores. Assim, elaboraram-se gráficos para examinar elementos de layout e sequências de leitura ordenados pela diagramação com base no uso de grids, como exemplificado na edição de Quatro cinco um (Figura 5), servindo de referência para a nova ordenação visual.

Figura 5 - Análise gráfica do jornal Quatro cinco um, edição n. 1.

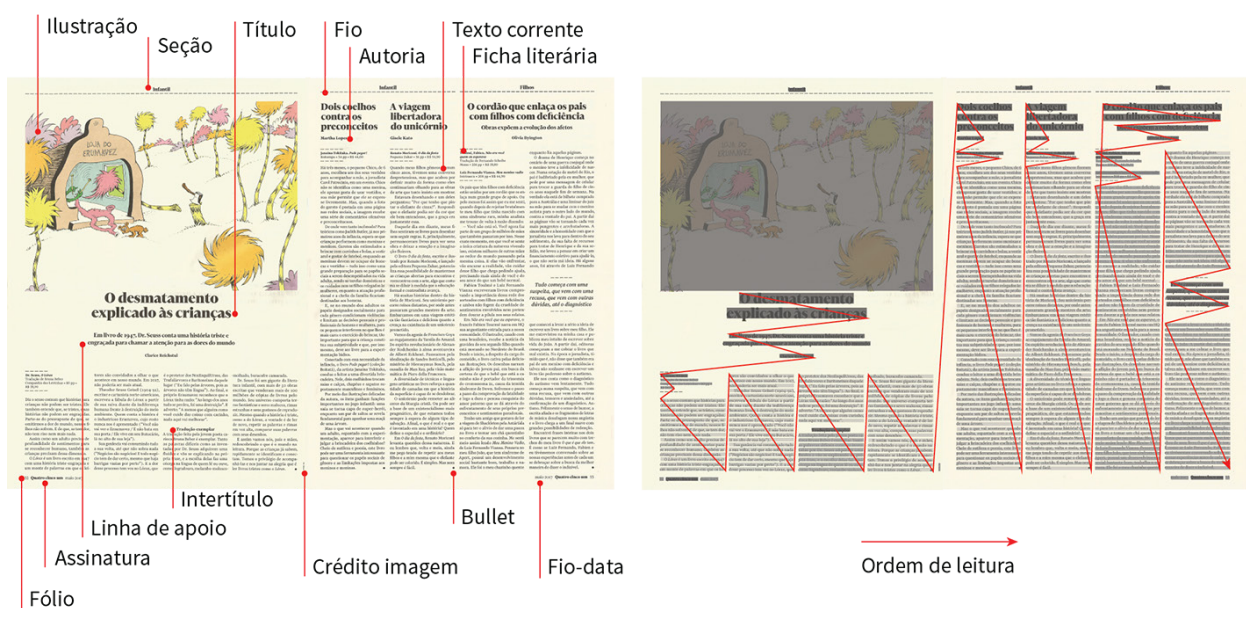

Fonte: elaboração dos autores (2018).

Comparados ao jornal Cidade Notícias, os estudos evidenciaram a falta de construção visual de uma hierarquia marcante no jornal de bairro, que, somada à presença imagética intensa, dispersava a visão com mais facilidade, quebrando a harmonia na leitura, além de, em alguns momentos, gerar ambiguidade sequencial. A distribuição misturada de tipos de conteúdo ao longo de toda a edição - que, segundo o editor, dá visibilidade e retorno aos anunciantes - causa, no entanto, sob aspecto visual, conflitos entre textos e imagens, prejudicando a leiturabilidade do tabloide. A presença de elementos de página, como nomenclatura de seção por exemplo, é fraca e apresenta muitas variações, tornando confusa a identificação e classificação dos conteúdos, os quais se encontram dispostos de maneira aleatória e oscilante de uma edição para outra.

Considerando o diagnóstico apresentado, levantando o conteúdo do jornal Cidade Notícias, a partir do formato definido, realizaram-se diversos estudos de grid, mancha gráfica e tipografia. Os projetos de grid foram inicialmente concebidos com base em construção geométrica, a fim de chegar a medidas também matematicamente coerentes, em equilíbrio com ajustes visuais, uma abordagem similar à exposta por Wollner (2003). O grid foi experimentado com texto de preenchimento lorem ipsum (LOREM, 2018) e com conteúdo de primeira página, intencionando estabelecer, simultaneamente à definição do grid, diretrizes visuais padrões para os variados elementos de página como informações de cabeçalho, texto corrido, manchete, chamadas, 
LIU, Eunice et al.

anúncios, fólio, entre outros, verificando a eficácia da estrutura dos grids em proposição, uma vez que a determinação dos elementos estava interligada.

Assim, ao longo de etapas de estudos e refinamentos, chegou-se a uma proposta de formulação de grid principal com 4 colunas, tendo variantes de 3 e 5 colunas, espaçadas entre si por $0,4 \mathrm{~cm}$ de medianiz, margens de $2 \mathrm{~cm}$ nas extremidades superior e inferior, e margens de 1,5 cm nas extremidades externa e interna. Verificou-se ser esta quantidade de colunas a média utilizada nos projetos de referência, sendo organizadas em relação ao formato de página às medidas de margens e mancha de texto, referenciadas pela diagonal do formato (Figura 6).

Figura 6 - Grid original do jornal Cidade Notícias (à esquerda) comparado ao novo grid proposto (à direita)

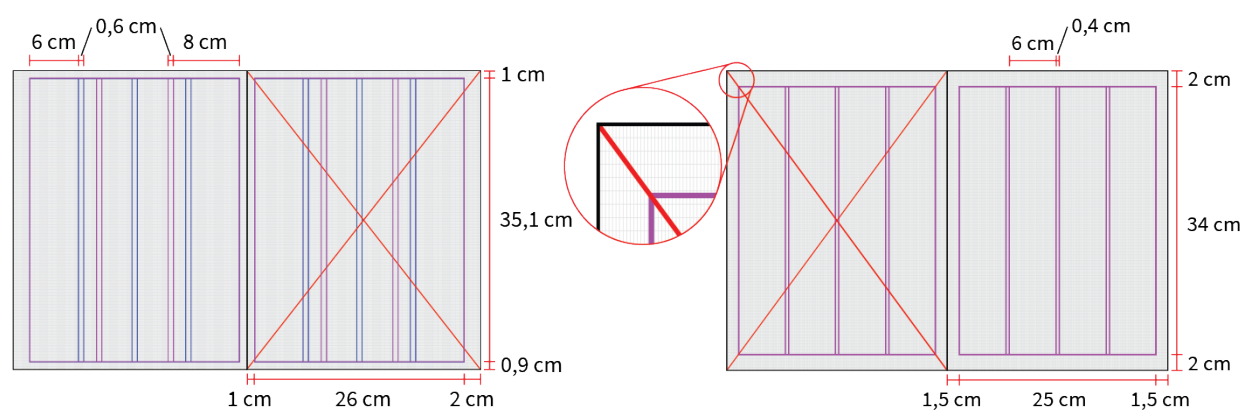

Fonte: elaboração dos autores (2018).

\subsection{Tipografia}

Seria possível enumerar um catálogo tipográfico, dada a quantidade de famílias empregadas no projeto editorial anterior do Cidade Notícias. Somada ao conteúdo de identidade do jornal, textos, seções, títulos e anúncios, essa variedade aparentemente arbitrária na escolha de tipos prejudica a legibilidade. Tschichold explica:

Ser capaz de ler uma cartilha ou mesmo um jornal, não faz de ninguém um juiz; em geral, ambos são fáceis de ler, ainda que mal. São decifráveis. Decifrabilidade e legibilidade ideal se opõem. A boa legibilidade resulta da combinação de um texto adequado e um método de composição apropriado (TSCHICHOLD, 1949, p. 27).

Tendo em vista que o jornal Cidade Notícias é organizado pelos próprios cidadãos, custeado por anúncios, e não tem fins lucrativos, verificouse a necessidade de desenvolver soluções que não trariam custos elevados para a implementação do projeto. No âmbito da tipografia, isso implicou uma condicionante quanto à seleção de fontes: a utilização apenas de famílias 
tipográficas que possuíssem licença gratuita, entretanto, sem diminuição do rigor no processo de escolha. Assim, buscou-se encontrar famílias tipográficas que demonstrassem excelência em quesitos essenciais apontados na literatura especializada, entre os quais destacam-se: desenho dos tipos, legibilidade, espaçamentos de entreletra e entrepalavra, rendimento - dada a limitada quantidade de páginas do tabloide -, estilos e variantes dentro da família (BRINGHURST, 2015; HENESTROSA; MESEGUER; SCAGLIONE, 2014; LIMA; GONC,ALVES, 2016). Tais aspectos se mostram importantes para um bom projeto editorial, como o de um jornal.

O processo de levantamento de famílias tipográficas então se deu por meio de serviços de licença gratuita, tendo sido Google Fonts (GOOGLE, 2018) a principal plataforma para tal definição. Realizou-se pré-seleção de fontes para texto e outras que possuíam particularidades e poderiam ser utilizadas para soluções gráficas diferenciadas no projeto, elegendo duas categorias de tipos: principais e complementares (Figura 7). Para a escolha final, realizaramse testes de diagramação, estudos de mancha gráfica com tamanhos e pesos diferentes, experimentando no grid com elementos e conteúdo de capa.

Figura 7 - Famílias tipográficas testadas para o novo projeto gráfico de Cidade Notícias.

\begin{tabular}{|c|c|c|c|}
\hline Roboto & Roboto Slab & Merriweather Serif & Source Serif \\
\hline Sans Serif| 18 pesos & Slab Serif | 4 pesos & $\begin{array}{l}\text { Merriweather Serif Light } \\
\text { Merriweather Serif Light Italic }\end{array}$ & $\begin{array}{l}\text { Source Serif ExtraLight } \\
\text { Source Serif Light }\end{array}$ \\
\hline Raleway & Sansita & Merriweather Serif Regular & Source Serif Regular \\
\hline Sans Serif | 18 pesos & Display| 8 pesos & Merriweather Serif Italic & $\begin{array}{l}\text { Source Serif SemiBold } \\
\text { Source Serif Bold }\end{array}$ \\
\hline $\begin{array}{l}\text { Lora } \\
\text { Serif } \mid 4 \text { pesos }\end{array}$ & $\begin{array}{l}\text { Crete Round } \\
\text { Slab Serif } \mid 2 \text { pesos }\end{array}$ & $\begin{array}{l}\text { Merriweather Serif Bold } \\
\text { Merriweather Serif Bold Italic } \\
\text { Merriweather Serif Black }\end{array}$ & Source Serif Black \\
\hline Oswald & Anton & Merriweather Serif Black Italic & Source Sans \\
\hline Display | 15 pesos & Display I 3 pesos & Merriweather Sans & $\begin{array}{l}\text { Source Sans ExtraLight } \\
\text { Source Sans ExtraLight Italic }\end{array}$ \\
\hline $\begin{array}{l}\text { Bitter } \\
\text { Slab Serif } \mid 4 \text { pesos }\end{array}$ & $\begin{array}{l}\text { Quicksand } \\
\text { Sans Serif | } 7 \text { pesos }\end{array}$ & $\begin{array}{l}\text { Merriweather Sans Book } \\
\text { Merriweather Sans Book Italic }\end{array}$ & $\begin{array}{l}\text { Source Sans Light } \\
\text { Source Sans Light Italic } \\
\text { Source Sans Regular }\end{array}$ \\
\hline $\begin{array}{l}\text { Lusitana } \\
\text { Serif } \mid 2 \text { pesos }\end{array}$ & $\begin{array}{l}\text { Bree Serif } \\
\text { Slab Serif | } 1 \text { peso }\end{array}$ & $\begin{array}{l}\text { Merriweather Sans Regular } \\
\text { Merriweather Sans Italic } \\
\text { Merriweather Sans Bold }\end{array}$ & $\begin{array}{l}\text { Source Sans Italic } \\
\text { Source Sans SemiBold } \\
\text { Source Sans SemiBold Italic }\end{array}$ \\
\hline $\begin{array}{l}\text { Lobster } \\
\text { Script | } 1 \text { peso }\end{array}$ & $\begin{array}{l}\text { Playfair Display } \\
\text { Serif } \mid \mathbf{1 2} \text { pesos }\end{array}$ & $\begin{array}{l}\text { Merriweather Sans Bold Italic } \\
\text { Merriweather Sans ExtraBold } \\
\text { Merriweather Sans ExtraBold Italic }\end{array}$ & $\begin{array}{l}\text { Source Sans Bold } \\
\text { Source Sans Bold Italic } \\
\text { Source Sans Black } \\
\text { Source Sans Black Italic }\end{array}$ \\
\hline
\end{tabular}

Fonte: Google (2018).

Por fim, visto que a versatilidade dos tipos constitui um fator central para a seleção tipográfica na composição de um jornal (CALDWELL; ZAPPATERRA, 2014), priorizou-se o uso das chamadas superfamílias. Estas apresentam fontes em versões sem serifa e com serifa, possuem larga variação de estilos e a escolha por esse tipo de família se mostrou favorável para o caráter do projeto editorial, que requer distinção de tipos de conteúdo e níveis de leitura, além de garantir, ao mesmo tempo, unidade de identidade. Optou-se então pelas fontes que possuíam dimensões estéticas e funcionais mais apropriadas à retórica da publicação trabalhada. As famílias tipográficas Merriweather e Source, ambas com opções sans e serif, foram eleitas para serem trabalhadas em texto corrente e em títulos, respectivamente. 


\subsubsection{Redesign da Marca}

Assim como as edições do tabloide, a marca do jornal carecia de padronização de versões e de consistência no uso. Portanto, o projeto de redesign incluiu também a reestruturação da marca, respeitando-se os traços de identidade existentes, como estilo tipográfico e paleta de cores, de modo a evitar uma ruptura abrupta do paradigma em curso, o que poderia causar estranhamento no público. Considerou-se também qualificá-la compativelmente ao novo projeto gráfico proposto.

A partir de uma larga seleção de famílias tipográficas, estas foram aplicadas ao nome do jornal para análise e avaliação da qualidade visual do conjunto de letras formadoras do nome e do desenho da marca. Simultaneamente, realizaram-se experimentações relativas ao espaçamento e à disposição de elementos de assinatura propostos: "Jornal de bairro de Curitiba" e "Santa Felicidade \& Região", informações contextualizadoras originalmente ausentes no jornal. $O$ intuito de incluir tais componentes consiste em estabelecer distinção em relação a outros tabloides.

Concluídos os estudos de seleção de tipos, disposição dos elementos que integram a marca, uso da paleta de cores e aplicações em conjunto, a marca foi então refinada até se atingir a versão final. Esta apresenta o nome "Cidade Notícias" escrito em uma mesma linha, com diferentes tratamentos gráficos nas duas palavras que o integram. Optou-se por conferir maior destaque à palavra "Cidade", composta com preenchimento na cor preta e sem contorno; já a palavra "Notícias" se diferencia pela aplicação de contorno vermelho sem preenchimento. A composição passou por refinamentos tipográficos, incluindo ajustes nos desenhos das letras, no espaçamento dos caracteres, na espessura do contorno e na disposição dos elementos, com a delimitação de um grid para formalizar tais relações. Como resultado, tem-se uma versão de redesenho construída de forma consistente e estruturada, mas sem perder a familiaridade da antiga marca (Figura 8).

Figura 8 - Marca original do jornal Cidade Notícias (à esquerda) comparada ao redesign proposto (à direita).

\section{CIDADE}

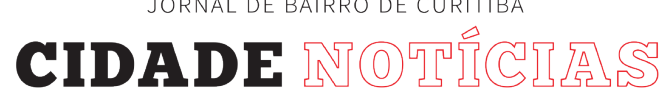

SANTA FELICIDADE \& REGIÃO

Fonte: Acervo Cidade Notícias e elaboração dos autores (2018). 


\subsubsection{Macrotipografia}

O jornal de bairro não possui manchas de texto muito extensas, no entanto, estas constituem um elemento fundamental na solução e organização visual editorial, além de caracterizar a identidade do tabloide. A escolha de fontes foi realizada estudando-se seu desempenho aplicado ao grid proposto, gerando alternativas visuais para os elementos de página prevalentes relativos à macrotipografia: texto corrente, manchetes, chamadas, fólio, informações de crédito etc.

Estudos de legibilidade, variando versões, corpo, entrelinha e combinações de fontes da família Merriweather, impressas em tamanho real em manchas de texto com ocupações variadas do grid, determinaram a escolha do tipo Merriweather Serif em corpo 11 pt, com 14 pt de entrelinha, para o texto na composição de notícias. Essa configuração apresentou bom rendimento e leiturabilidade para vários públicos, considerando especialmente os adultosidosos, faixa etária predominante entre o público leitor do jornal.

A estruturação de um grid mais consistente, apresentado na seção 4.2, em paralelo com a escolha de tipos, foi fundamental para organizar a informação da página e conferir uma ordem de leitura mais clara e objetiva. Isso proporcionou a obtenção de uma cor tipográfica homogênea, seguindo as diretrizes de Bringhurst (2015, p. 32):

[...] o tipógrafo, assim como o escriba, procura tecer o texto da maneira mais homogênea possível. Do mesmo modo, os bons tipos são desenhados para produzir uma textura vivaz e homogênea. [...] E isso depende de quatro fatores: 0 desenho do tipo, o espacejamento das letras, das palavras e das linhas. Nenhum é independente do outro.

Dentro dessa estrutura, um parâmetro fundamental diz respeito ao comprimento das linhas de texto, geralmente expresso pela quantidade média de caracteres que cada linha suporta (cpl). De acordo com Felici (2012), os valores adequados para a composição tipográfica variam entre $27 \mathrm{cpl}$ (mínimo), $40 \mathrm{cpl}$ (ideal) e $70 \mathrm{cpl}$ (máximo). No redesign de Cidade Notícias, buscou-se respeitar essas diretrizes, com média de $27 \mathrm{cpl}$ na configuração principal de 4 colunas.

Conferir unidade visual e identidade ao jornal constituiu um desafio tão importante quanto melhorar a legibilidade das páginas, antes poluídas, construindo distinções visuais e hierárquicas de leitura, de maneira equilibrada. Uma clara distinção de corpos e pesos para cada finalidade ou tipo de informação organizada pelo grid permitiu hierarquizar o conteúdo, trabalhando em páginasmodelo, como denominado por Tschichold (1949, p. 26), e conforme ilustrado na Figura 9.

Projética, Londrina, v.9, n.2 supl. p. 333-348, nov. 2018 
Tipografia perfeita depende de perfeita harmonia entre todos os seus elementos. Devemos aprender, e ensinar, o que isto significa. A harmoniaé determinadapor relações ou proporções. Proporções escondem-se em toda parte: na amplitude das margens, nas relações recíprocas de todas as quatro margens do livro [ou jornal], na relação do entrelinhamento da mancha com as dimensões das margens, na colocação do número da página com respeito à mancha, na eventual diferença entre o espacejamento das letras maiúsculas e o espacejamento do texto e, não menos importante, no espacejamento das próprias palavras. Em suma, afinidades escondem-se em qualquer parte e em todas elas.

As páginas modelo, de capa e dupla interna, permitiram estudar elementos variáveis de conteúdo existentes no jornal. Para a capa, sugeriu-se a criação e nomenclatura do espaço "Voz da cidade" visualmente delimitado por um box em forma de vírgula expandida, que também remete a um balão de fala, retratando a tipografia como imagem, tratando-se de um canal para moradores expressarem de maneira concisa suas opiniões, incentivando a interação do leitor com a publicação. Ainda na capa, resgatou-se o box de telefones úteis, presente em algumas edições antigas do Cidade Notícias, informação de grande relevância em local de rápida visualização.

Quanto ao campo determinado para os anúncios, se manteve distribuído ao longo do jornal, organizados, no entanto em áreas delimitadas, preferencialmente alinhadas por faixas que realizem a distinção visual de ocupação em relação ao texto, em tamanhos que podem variar de acordo com módulos padrões definidos pelo grid e área de mancha (página inteira, meia página, 1/4 de página, $\bigotimes$ de página, com 1 a 4 colunas de largura).

O expediente na segunda página foi separado das demais seções de conteúdo e anúncios por um box sem contorno e com preenchimento, distinguindo-o do restante das informações, tendo a marca aplicada em sua versão normal e as informações, antes apresentadas de maneira corrida, diagramadas de modo mais elaborado, destacando informações de importância.

\subsubsection{Microtipografia}

No que tange os detalhes de composição tipográfica, o projeto de redesign realizou refinamentos gráficos visuais em elementos da capa, como a organização do cabeçalho, propondo a adição descritiva do jornal como assinatura assim como a região de circulação com a marca redesenhada, em equilíbrio com área de respiro, branca, pouco presente nas edições, destacando essas informações, distinguindo-as com clareza de outras informações como o número do jornal, que passou a ocupar o canto superior esquerdo do layout, juntamente com a 


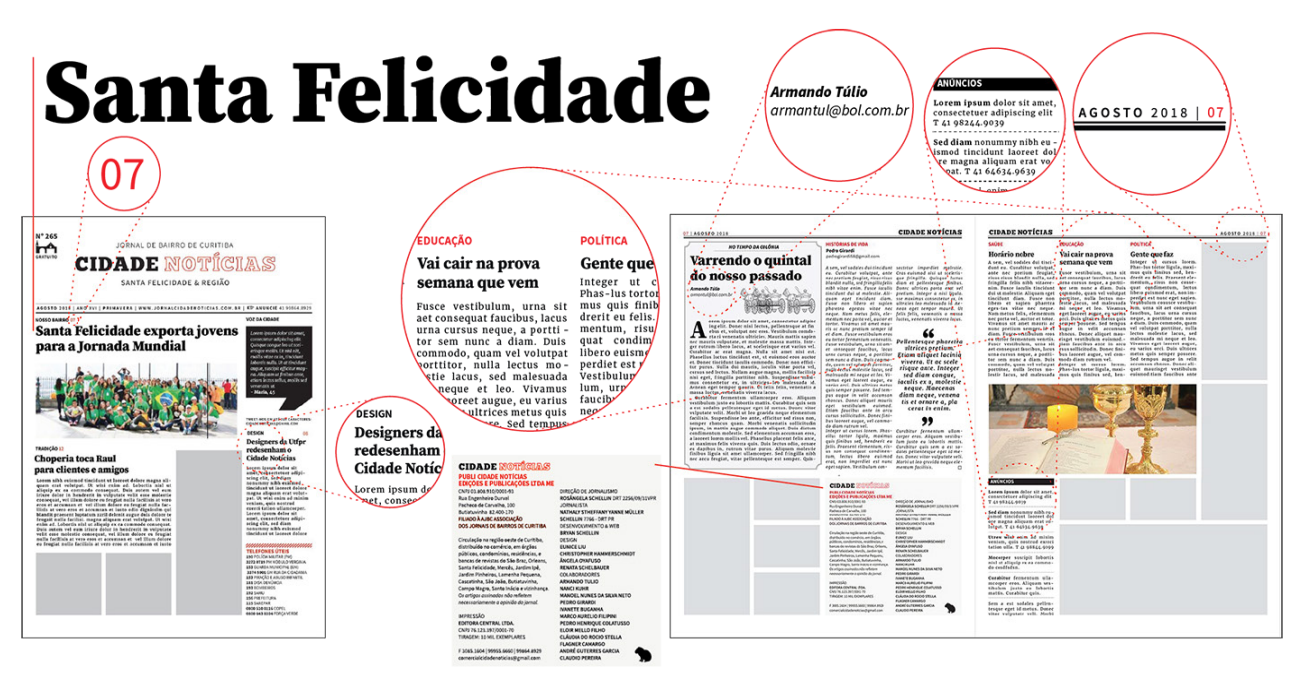

Fonte: elaboração dos autores (2018).

informação de gratuidade da distribuição, que antes se mesclava ao conteúdo editorial, diminuindo sua visibilidade. Adicionou-se o desenho de um ícone do portal de Santa Felicidade, como um código visual que reforça a informação da assinatura ao mesmo tempo que agrega identidade. Informações como data, ano do jornal, estação da publicação - proposta uma vez que a circulação é mensal -, site e telefone de contato são envolvidos por meio de fios de 0,5 e 2 pt, elemento gráfico que ancorará a assinatura nas páginas do jornal. A informação de contato é destacada pela presença do marcador tipográfico manicule, originalmente concebido para este fim (Figura 10).

Figura 10 - Cabeçalho no redesign do Cidade Notícias.

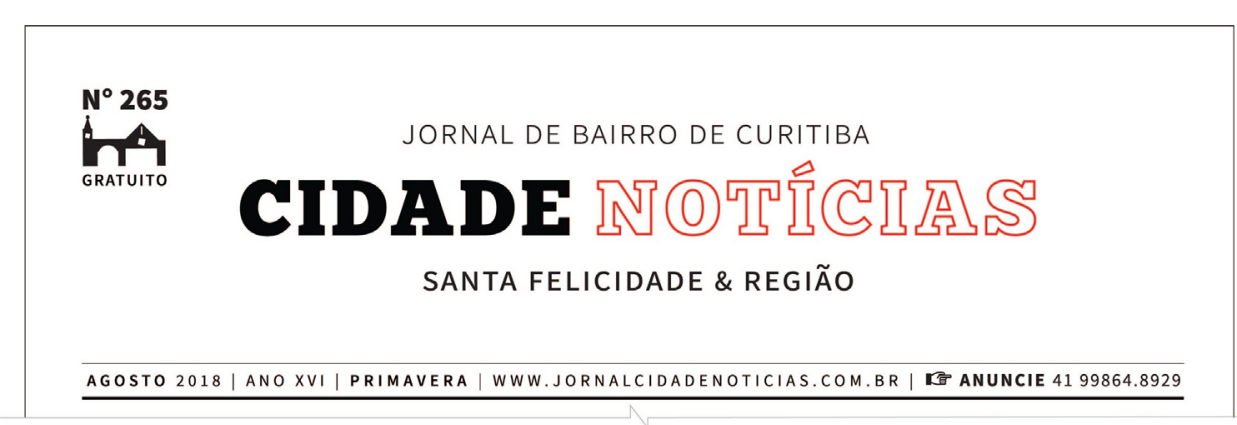

Fonte: elaboração dos autores (2018).

Ainda na capa, as seções são indicadas pelos tipos sem serifa Source Sans Bold, com as remissões de fólios grafadas na mesma fonte, porém em peso regular e em vermelho, com o objetivo de separar as informaç̃oes visualmente em também destacar o número da página. Nas páginas internas, as seções mantêm a formatação básica, mas inteiramente escritas em vermelho, contrastando com a mancha. 
Foram definidos padrões para tipos de composição de texto como: manchete principal de capa, com tipos grafados em corpo 36 pt e entrelinha 39 pt, prezando destaque e visibilidade a distância; chamadas de notícias, em destaque e em corpo maior que o texto corrente, utilizando-se o tipo Source Serif Black 18 pt e entrelinha 21 pt; combinados ao texto corrido em Merriweather Serif em 11/14 pt, com a entrelinha sempre 3 pontos acima do corpo, realizando-se ajuste de alinhamento de colunas pelas entrelinhas entre os diferentes corpos.

Seções tradicionais do jornal receberam tratamento diferenciado, como a coluna intitulada No tempo da colônia, com o uso de uma ilustração de carroça junto, referindo à época e distinguindo-a. No expediente editorial, por sua vez, uma ilustração da silhueta de capivara, animal símbolo da região, confere um tom descontraído. Outros elementos gráficos, a exemplo de fios, boxes, letras capitulares e olhos (janelas com destaque de texto), foram propostos para organizar as informações, atrair visualmente e construir identidade. A assinatura do jornal, nos cabeçalhos das páginas internas, tem posicionamento espelhado na dupla, com uso de um fio duplo para separá-la do restante das informações de mancha, remetendo ao elemento de capa, com a marca em versão monocromática reduzida preenchida em preto e informações referentes ao mês da publicação e o fólio em vermelho alinhadas à margem externa (Figura 11).

Figura 11 - Microtipografia no redesign do Cidade Notícias.

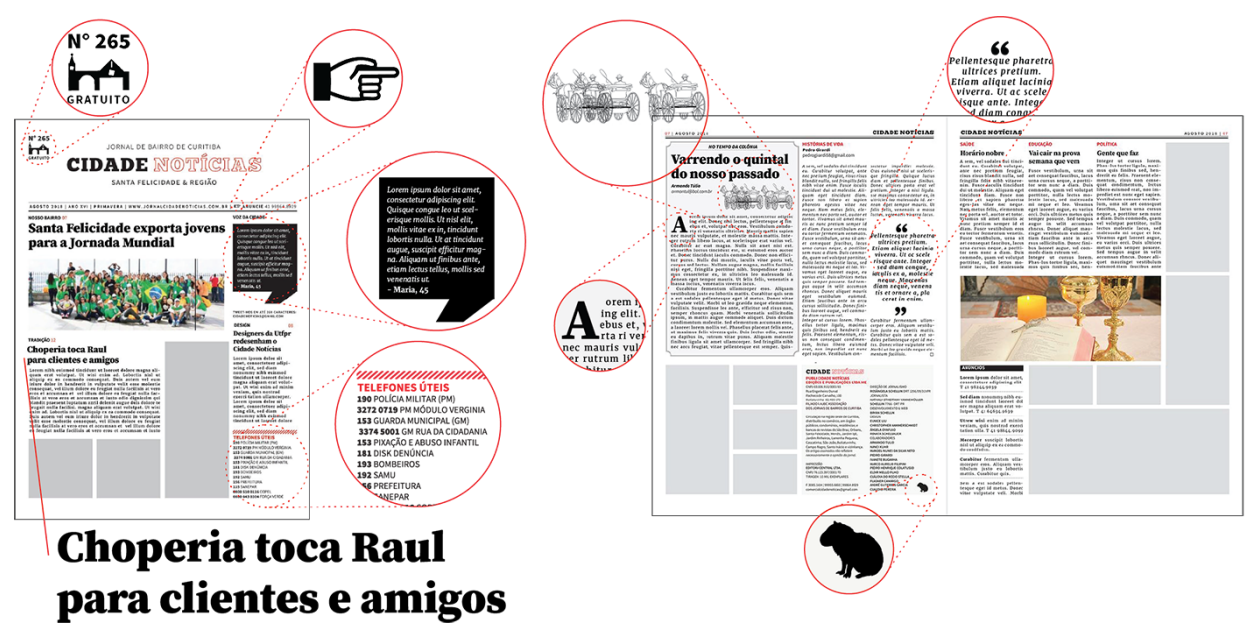

Fonte: elaboração dos autores (2018).

\section{REFLEXÕES FINAIS}

O redesign do jornal de bairro Cidade Notícias buscou, por meio de recursos gráficos editoriais, propor um bom design, dando uma nova visualidade para o conteúdo entregue ao público pelo tabloide, não se tratando apenas de uma mudança estética, mas, sobretudo, compreendendo o papel 
desempenhado pelo jornal que se insere no cotidiano das pessoas, respeitando sua história, apresentar as informações de maneira clara, objetiva, funcional e bela para atuais e novos leitores:

\begin{abstract}
O conteúdo é basicamente a idéia, é isso que é o conteúdo. Forma é como você trata a idéia, o que você faz com ela. Este é exatamente o significado do design: o conflito entre forma e conteúdo, sendo a forma o problema. Ou seja, é como você faz, como você mostra algo, como você pensa, como fala, como dança; a coreografia é o conteúdo. [...] Por um lado, isso não é simples, mas, por outro, é. O casamento da forma com o conteúdo é a realização do design (RAND, 2010, p. 46-47).
\end{abstract}

Os elementos visuais, sua ordenação, a relação de cheios e vazios, as escalas, os pesos geram níveis de hierarquia e leitura, densidades e direcionamento de olhar, comunicando a informação de maneira mais efetiva, por meio da visualidade, como afirmava o manifesto Topografia da tipografia, de El Lissitzky, publicado em 1923: "Na superfície escrita, as palavras são percebidas pelo olhar, não pela audição" (LISSITZKY, 1923, p. 24). Bringhurst, em sua introdução para A forma do livro, obra consagrada de Tschichold, afirma que "Como outras artes, da medicina à música, a tipografia também requer estreita proximidade e distância. Isso não é o que parece, um senso esquizofrênico de escala, mas uma espécie de tensa completude" (BRINGHURST, 2007, p. 11). A tensão é a referida harmonia, que será verificada pelos curitibanos quando o novo projeto gráfico for implementado. Para tanto, o trabalho terá continuidade com os desdobramentos do padrão visual proposto às demais seções de conteúdo do jornal, a que se seguirão as etapas de especificação de aspectos técnicos de produção do material gráfico e o posterior monitoramento dos resultados junto aos leitores. Assim, será possível analisar o impacto do projeto em pontos essenciais, como o número de leitores alcançados e a qualidade da experiência de leitura.

\title{
AGRADECIMENTO
}

Corpo editorial de Cidade Notícias. 


\section{REFERÊNCIAS}

AMBROSE, Gavin; HARRIS, Paul. Design básico: grids. Porto Alegre: Bookman, 2009.

BRINGHURST, Robert. Elementos do estilo tipográfico: versão 4.0. 3. ed. São Paulo: Cosac Naify, 2015.

BRINGHURST, Robert. Introdução. In: TSCHICHOLD, Jan. A forma do livro. São Paulo: Ateliê, 2007.

CALDWELL, Cath; ZAPPATERRA, Yolanda. Design editorial: jornais e revistas / mídia impressa e digital. São Paulo: G. Gili, 2014.

FELICl, James. The complete manual of typography: a guide to setting perfect type. 2. ed. Berkeley, CA: Peachpit, 2012.

GOOGLE Fonts. Disponível em: <https://fonts.google.com/>. Acesso em: 18 jan 2018.

HENESTROSA, Cristobal; MESEGUER, Laura; SCAGLIONE, José. Como criar tipos: do esboço à tela. Brasília: Estereográfica, 2014.

LIMA, Mary Vonni Meürer; GONÇALVES, Berenice Santos. Seleção tipográfica no contexto do design editorial: uma abordagem qualitativa para identificação de critérios. DATJournal, São Paulo, v. 1, n. 1, p. 107-115, 2016.

LISSITZKY, El. Topografia da tipografia. 1923. In: BIERUT, Michael; HELFAND, Jessica; HELLER, Steven; POYNOR, Rick. Textos clássicos do design gráfico. São Paulo: M. Fontes, 2010.

LOREM ipsum. All the facts: Lipsum generator. Disponível em: <https://www. lipsum.com/>. Acesso em: 18 jan. 2018.

MUNARI, Bruno. Design e comunicação visual. São Paulo: M. Fontes, 2002. RAND, Paul. Conversa um. In: KROEGER, Michael. (Org.). Conversas com Paul Rand. São Paulo: Cosac Naify, 2010. p. 21-47.

SLESS, David. Collaborative processes and politics in complex information design. In: ALBERS, Michael J.; MAZUR, Beth. (Ed.). Content and complexity: information design in technical communication. London: Lawrence Erlbaum, 2003.

TSCHICHOLD, Jan. Barro na mão do oleiro. 1949. In: A forma do livro. São Paulo: Ateliê, 2007. p. 25-29.

WOLLNER, Alexandre. Making of. In: Alexandre Wollner: design visual 50 anos. São Paulo: Cosac Naify, 2003. p. 1-15. 